\title{
DESBORDAMIENTO DE LA PERSONALIDAD Y HORROR MORAL EN LA GRAN SEMÍRAMIS, DE VIRUÉS
}

\author{
Luis Caparrós Escalante \\ Universidad de Valladolid
}

A la última generación de trágicos del siglo XVı se les ha caracterizado, globalmente, como trágicos del horror'. No es éste lugar para un desarrollo de las peculiaridades que justificarian tal denominación, aunque sí cabe destacar el relevante influjo de Séneca, visible también en el fondo estoico que alimenta ese motivo dramático. Entre todos estos autores, si hay uno a quien cuadre perfectamente el título de trágico del horror es, sin lugar a dudas, el capitán valenciano Cristóbal de Virués ${ }^{2}$.

Virués es personaje adusto y agrio, según nos lo reflejan sus propias obras. Pese a grandes coincidencias biográficas, en ningún momento muestra la mirada tolerante y socarrona de su contemporáneo Cervantes ${ }^{3}$..Como él, Virués combatió en Lepanto y su nombre se acompaña, al frente de sus tragedias, con el apelativo de "capitán». Como él, pudo enriquecerse con experiencias humanas y literarias en Italia. Como él, su ideario dramático entrará pronto en contradicción con la avasallante Comedia. Como él, finalmente, Virués no parece encontrar acomodo en la España filipista. Sin embargo, pese a los paralelismos, sus experiencias vitales desembocan en soluciones divergentes. Cervantes apuesta por la vida, sin perder por ello su fondo moral y ético. Virués, en cambio, nunca afirma con sus negaciones, sino que se encierra en un rígido ascetismo inhumano, donde el amor o la

I Alfredo Hermenegildo, La tragedia en el Renacimiento español, Planeta, Barcelona, 1973. pp. 155 y ss.

2 lbidem. p. 216: "Virués intentó poner de moda a Séneca y sus obras resultan senequianas sólo hasta cierto punto. Los parecidos son grandes, pero quedan exageradas las cualidades en el autor valenciano".

3 Ibidem. p. 210: «Uno y otro se sitúan frente al mundo en una dialéctica de afirmación del yo tipica de los españoles que luchaban desesperadamente por abrirse un espacio, una "morada vital" personal en la sociedad española del siglo xvı. Si es evidente que Cervantes fue cristiano nuevo, Virués es sospechoso de serlo también". 
mujer son trasunto del demonio tentador y hasta el gobierno - pese a retóricas alabanzas a Felipe II- se confunde con la ambición o la tiranía ${ }^{4}$.

La intransigencia moral del capitán participa plenamente del carácter admonitorio y morboso de las antiguas prédicas. Como aquéllas, sus dramas son un esfuerzo constante por mostrar las espantosas consecuencias de la debilidad humana. Al final, cuando el personaje de Tragedia hace su aparición, debiera ser posible percibir bajo el tablado el hedor azuferino de los infiernos. Aunque tras todo ello esté el recuerdo de Séneca, del Séneca trágico, su presencia no basta para explicar este insistente regodeo en los crímenes más atroces, en los adulterios más complejos, en el incesto o las transgresiones sexuales. El horror no surge sólo de la sangre, de la violencia fisica, sino que es - sobre todo- horror moral. Séneca es una referencia obligada y compartida con otros dramaturgos, pero el horror está, fundamentalmente, en el propio Virués.

La gran Semiramis ofrece un buen muestrario de motivos de carácter horroroso y, además, permite su confrontación con tratamientos anteriores y posteriores del mismo tema ${ }^{5}$. A diferencia de las fuentes 0 , con posterioridad, de Calderón, la protagonista aparece en escena sin ningún condicionamiento previo. No pesa sobre la bella Semíramis ningún vaticinio trágico ni su origen se tiñe -salvo al final, $y$ sin relevancia dramática- de claves denigratorias. A Virués le preocupa, ante todo, mostrar el concepto de responsabilidad personal, de autodominio, y sobre él no pueden pender las estrellas. A un fin moral sin fisuras corresponde un desarrollo limpio de condicionantes e, incluso, dibujado con trazos gruesos. No cabe, por tanto, el bello pero ambiguo conflicto dramático calderoniano entre libertad y destino.

El juego antitético recorre todo el tema desde el comienzo. Razón frente a Pasión es antitesis dominante y de ella se derivan las secundarias: autodominio/ambición, valor/crueldad, libertad/tiranía, etc. Pero Virués, pese a esto, no sabe o no quiere reflejar dramáticamente estas contradicciones. El polo negativo es el centro real de la acción. La vida, el dibujo multipolar y abigarrado de la vida, se resuelve finalmente en los tintes negros de la muerte: «Miserable mortal; tu vida es muerte» ${ }^{6}$. La única posible respuesta de -Virués viene a ser, tal como lo expresa en El Monserrate, la negación:

4 Cfr. Alfredo Hermenegildo, "Adulación, ambición e intriga: los cortesanos de la primitiva tragedia española», Segismundo, 25-26, 1977, pp. 43-87.

5 Vid, para las fuentes: Cecilia V. Sargent, A Study of the Dramatic Works of Cristobal de Virués, Instituto de las Españas, Nueva York, 1930, pp. 68-75. Para su tratamiento por Calderón: Gwynne Edwards (ed.), Pedro Calderón de la Barca, La hija del aire, Tamesis Books, Londres, 1970; Francisco Ruiz Ramón, Calderón y la tragedia, Alhambra, Madrid, 1984, pp. 4-6; Alfredo Hermenegildo, "La responsabilidad del tirano: Virués y Calderón frente a la leyenda de Semíramis", en Actas del Congreso Internacional sobre Calderón y el Teatro del Siglo de Oro, II, CSIC, Madrid, 1983, pp. 897-911.

6 Cristóbal de Virués, «Historia del Monserrate», en Poemas épicos, I, BAE XVII, Madrid, (1854) 1945, p. 542. 
Las lisonjas, los cargos, la riqueza, los regalos, los gustos, las dulzuras, los linajes, las gracias, la belleza, los descansos, las prósperas venturas, no te engolfen, mezquino, en la braveza de su revuelto mar de desventuras, porque no embista por tu mal gobierno tu rota barca en rocas del infierno?

La vida -muerte, como se ha visto- se concibe bajo las formas ascéticas del soldado en campaña: guardia permanente, combate frente a las añagazas de los sentidos, renuncia al goce. Asi se muestra en el caso del ermitaño penitente Garín, protagonista de El Monserrate, obra que es -o pretende ser, pese a su falta de nervio- un poema épico, lo cual ya es bastante significativo .

Si Garín es el modelo, las tragedias reflejan las consecuencias de no seguir ese áspero camino de salvación. Su tema real es el descenso a los infiernos, y los "exemplos de virtud»-prácticamente inexistentes-se muestran, tal como indica el prólogo de La cruel Casandra, «tal vez por su contrario el vicio"." El Virués trágico aparece fascinado por el Mal, acechante tras cada debilidad humana, agazapada en cada aspecto risueño de la existencia, riquísimo e inagotable en posibilidades frente a la unicidad del Bien, del comportamiento virtuoso.

El auténtico motor dramático se encuentra, en consecuencia, en el camino de descenso a los infiernos. La acción de La gran Semíramis se desencadena por la quiebra de los estrechos límites de la virtud. A partir de ahí, una vez retirada la razón alerta, la pasión produce el desbordamiento del mal, una auténtica caida de los personajes al vacio de las posibilidades. Sin orden, sin cifra o número, esos personajes se pierden en la laberinto de su propia personalidad desparramada. La ruptura de la contención ética tiene su correlato natural en la pincelada gruesa de los caracteres y las acciones: ese horror moral se expresa literalmente por la exageración y el tremendismo. Paradójicamente, al mostrar los riesgos de la falta de diques morales, el propio Virués naufraga en la incontinencia dramática: retrata monstruos, no seres humanos.

7 Ihidem, p. 525.

8 Virués llega al extremo de ver debilidad en la lglesia de su tiempo:

Trocadas ioh gran Dios! están las suertes

en esta edad a la virtud esquiva;

más blandura en la Iglesia y más terneza,

$y$ en los cristianos menos fortaleza.

(Ibidem, p. 557)

9 Poctas dramáticos valencianos, l, ed. E. Juliá Martinez, Real Academia Española, Madrid, 1929, p. 59. 
Weiger ha señalado, acertadamente, que esta tragedia trata de la «multiplicidad de carácter que en cada ser residen ${ }^{10}$. En efecto, Semíramis va a ser mujer-hombre-, rey-reina, madre-amante, esposa-soldado, y etc. Pero conviene señalar las posibles causas y sentido de esas transformaciones, que se dan en un crescendo marcado por la progresiva transgresión de los límites. Para poder comprenderlo, el personaje de Semíramis debe ser visto en movimiento, en la ordenada sucesión de los actos. Al comienzo del drama solamente hay posibilidades, pero no realidades efectivas, desplegadas después de un modo progresivo. El parlamento del rey Nino a la recién llegada Semíramis está cargado de resonancias platónicas: ella es sombra de un «divino original», más que verdadera mujer. En suma, Nino intuye tras la apariencia de Semíramis - tras su sombra - una esfera ideal, aún intangible, donde se guardan todas sus posibles imágenes. Y no deja de ser significativo que Virués invierta el orden de la escala platónica: la belleza y el ingenio de Semíramis no son, precisamente, el reflejo de un angel del Paraíso ${ }^{11}$.

En ese primer acto aparece como la fiel esposa de Menón, privado del rey Nino. Aparentemente, como acabamos de ver, nada sugiere maldad en ella ni existen sombras fatales sobre su destino. Pero es sólo apariencia, pues su misma condición de mujer conlleva ya un riesgo considerable, vista la extremada misoginia de Virués. Además, acude junto a su marido con ropas de hombre y, lógicamente, no cabe suponer el menor tinte populista o de halago erótico en ese disfraz. La explicación-dada por ella misma-de que así viaja más segura y desembarazada, no nos sirve. No estamos ante una de las alegres travestidas de la Comedia y, por tanto, sólo cabe pensar que Semíramis, aún sin clara conciencia de ello, ha transgredido los límites de su condición femenina. Si además de ser mujer es hermosa, inteligente y de carácter decidido, fácilmente pueden medirse los riesgos a que se enfrenta. Cuanto mayores sean los dones naturales y las "posibilidades de carácter", mayores serán también las tentaciones y mayor el esfuerzo de la virtud para dominarlas.

Desde el comienzo, Semíramis despliega su rica personalidad y, como consecuencia, tienta a Fortuna. Tras la conquista de Batra, debida a su ingenio, el rey Nino ha de fijarse necesariamente en la hermosa estratega. Sin embargo, pese a lo anterior, la actitud contenida de Semíramis desmiente todas las sombras que ella misma ha convocado. Es ella quien, frente a los halagos del Rey, le insta a ser razonable y a no dejarse llevar por la pasión: «De la pasión retiras/la razón...." ${ }^{12}$. Es ella, del mismo modo, quien expresa esa moral militante que defiende Virués:

10 John G. Weiger, Hacia la Comedia: de los valencianos a Lope. Cupsa, Barcelona, 1978.

p. 71

11 Vid. Poetas dramáticos valencianos, I, p. 30.

12 Ibidem, p. 31. 
Vista desde la perspectiva de la progresión dramática, Semíramis aparece en este primer momento como vencedora de sí misma ${ }^{14}$. Ello no quiere decir que su comportamiento la convierta en víctima, bien sea como negadora de su propia ambición o como presa de un rey tirano. Menón, su esposo, es la victima real de ese combate. El acto se cierra con su suicidio, colgado de la misma soga con que murió el monarca derrotado de Batra. Pero la muerte de Menón aúpa a Semiramis a la esfera del poder.

Hasta ahora, el sentido dramático exigia su autodominio. En el segundo acto se dará, con todas las consecuencias, la ruptura de la anterior contención. Ella no sigue entonces su propio consejo: vencedora en todas las pruebas, tienta los límites de su fortuna y, por añadidura, los de su propia virtud. La estratagema con la que toma el poder, pese a hacerse en nombre de su anterior marido, supone conscientemente un grave paso más allá de lo razonable:
Los filos azerados, rigurosos, que en la baina mil años a que encierra mi coraçón, dexad que aora corten, que tiempo avrá después que se reporten ${ }^{15}$.

Ahí está, si no su error, sí la clave de su desmedido comportamiento siguiente. Ya no habrá tiempo para que esos "filos azerados» se reporten. Una vez puesta en movimiento la máquina de sus posibilidades, de sus imá-

13 Ihidem. La misma idea se expresa en La hija del aire, de Calderón, aunque en boca de Menón:

Señor, vencerse a si mismo un hombre es tan grande hazaña. que sólo el que es grande puede atreverse a ejecutarla.

(Pedro Calderón de la Barca, Ohras completas. Dramas, Aguilar, Madrid, 19412, p. 593).

14 No parece exacto, por consiguiente, atribuir a Semiramis un «silencio otorgador», como sugiere Hermenegildo (La tragedia, p. 219). Weiger, por su parte insiste en que "Semíramis no se opone, guardando un elocuente silencion (Op. cit., p. 82). Lo cierto es que, si bien no ofrece una resistencia tenaz y extremada, no deja de mostrar una correcta actitud frente a las pretensiones del Rey. Semiramis está, si se quiere, en el mismo límite de la corrección, pero de eso se trata: la acción surge de la quiebra del limite.

15 Poefas dramáaricos valencianos, I, p. 38. Calderón recoge la misma idea:

¿Qué importa que mi ambición

diga que ha de despeñarme

del lugar más superior.

si para vencerla a ella

tengo entendimiento yo?

(P. Calderón de la Barca, Obras, p. 573). 
genes posibles, la misma inercia acelera su marcha en busca de su desarrollo pleno. La falta de contención aviva el apetito de poder, sea en el plano sexual, sea en el político. Así lo señala el cortesano Zebalo, mediante la significativa imagen de soltar las riendas:

I el ver que cuanto emprende le sucede según su pretension, hará que emprenda cualquiera empresa, pues la dicha ecede a la virtud i a cualquier otra prenda, $i$, quien dichoso se conoce, puede soltar en todo a su plazer la rienda ${ }^{16}$.

Semiramis se convierte en devoradora de cuanto la rodea, como cifra o resumen de todos los matices del poder. Al desplegarse, pronto rebasa el marco de su anterior figura de reina consorte y, como imagen de su hijo -a quien suplanta vestida de hombre-, pretende ser rey y reina a un tiempo:

No ai cosa en que repare ya ni dude; mañana seré rei i reina junto ${ }^{17}$.

La muerte de Nino cierra el segundo acto, del mismo modo -y con el mismo sentido- que la de Menón cerraba el primero. Cada una de estas muertes sirve al engrandecimiento de la reina, pero si entonces ella era causa indirecta, ahora es la ejecutora.

El tercer acto supone la culminación del proceso de desbordamiento de la múltiple y contradictoria personalidad de Semíramis. Su engrandecimiento es, al mismo tiempo, engrandecimiento del reino, pero a ella no le basta con disfrutar el poder, sino que necesita fundirse con él y ser -con pasión omnivora- el mismo poder hecho carne. Su deseo es dificilmente saciable, pues el poder es calidoscópico, compuesto de múltiples facetas, imposible de abarcar por una sola persona. De este modo, los rasgos más monstruosos de Semíramis surgen de la dificultad para reducir a unidad esa suma abigarrada de contrarios.

Su necesidad de alimentarse de víctimas, de sacrificar en el tálamo los cuerpos de sus amantes - como heredera de las serranas del Arcipreste-, es no solamente manifestación de su poder, sino fundamento del mismo. Nunca se entrega. Goza, y su gozo destruye. Semíramis devora cuerpos y no almas, pues nadie puede saciar su deseo.

16 Poetas dramáticos valencianos, I, p. 50 .

17 Ibidem, p. 45. 
En diversos pasajes se señala que es incapaz de amar, de enamorarse. Ciertamente, ella es mucho más rica en matices y posibilidades que cuantos la rodean. Menón se rinde a sus pies como si fuese una diosa. El tirano Nino sucumbe a su sugestión y le ofrece el trono, que es tanto como ofrecerle su propia vida. Zelabo, al fin, es simplemente un cuerpo hermoso. Si Semíramis no se enamora es porque no tiene un amante correspondiente. Como dice Zapiro, sólo el poder la mueve:

$\quad$ Que su altivo coraçón
ni tiene amor ni afición
sino a ser reina i mandar.
Este sólo es su exercicio,
éste sólo es su desseo,
aunque tras esto bien creo
que seguirá cualquier vicio.

La ambición, volcada hacia su propio yo, es su sentimiento dominante. Su deseo de poder es -al no conocer límites- un deseo de totalidad, pero la ósmosis de su yo con el poder -con todos los matices del poder-naufraga en la dispersión.

Como se ha señalado ya, el amor incestuoso hacia su hijo Ninias es una forma de narcisismo ${ }^{19}$. Pero Ninias - un otro-condensa en unidad el propio yo disperso de Semíramis. Sólo ante él puede sentir el amor, pues Ninias es su propia imagen objetivada y, por tanto, el único posible amante correspondiente. Por él, la ambición se cubre con los rasgos del amor. El objeto de la pasión amorosa es, de este modo, una personificación objetivada del poder, y éste se cubre el rostro con sus mismos rasgos, con su máscara. Sin embargo, el amor supone también su rendición ante el objeto amado y, en consecuencia, su muerte. Al final, Semíramis comparte el destino de sus antiguos enamorados, Menón y Nino, tan avariciosos de poder como ella misma, pero -también como ella misma ahora- perdidos por amor hacia su imagen ${ }^{211}$. Si recobra la unidad perdida es bajo las formas engañosas del

ix Ibidem, p. 41 .

14) J. G. Weiger, Op. cit., p. 81 : «El amor incestuoso es el climax del amor propio: Semíramis se enamora de sí misma cuando, por fin, deja que Ninias se vista de hombre. Es decir, la persona que ve es el vivo retrato de lo que ella misma había personificado".

20) Virués-en el prólogo a La gran Semiramis-aclara que ha pretendido que cada uno de Ios actos constituya, por si mismo, una tragedia. De este modo, cada parte acaba con una muerte: Menón en la primera, Nino en la segunda y Semiramis en la tercera. Lo más relevante, desde nuestro punto de vista, es la perfecta simetria entre las tres: todos -incluso ellamueren por rendirse apasionadamente a Semíramis. Por otro lado, la muerte de Nino y la de Semiramis ofrecen una correspondencia aún mayor: en el primer caso se invoca el recuerdo de Menón y en el segundo el de Nino; y en el primero se urde una grotesca explicación de carácter metamórfico que se repite en el segundo. Con todo ello se subraya, evidentemente, la continuación del desorden: Ninias es Semíramis. 
amor, tras el que se oculta la muerte. "Miserable mortal; tu vida es muerte».

La posible lectura política de la tragedia no puede desligarse de lo anterior. Si en el plano moral -prioritario para Virués- el tema es el desbordamiento de los límites, en el plano político encontramos la misma tendencia omnivora y multifacética, devoradora de hombres, en el Estado absolutista. Política y moral no son dos ámbitos diferenciados para el capitán Virués, tan antimaquiavélico como sus contemporáneos españoles. Por ello, la eficacia en el gobierno, la magnificencia del Estado, no supone el último fín del gobernante ni mucho menos le confiere carta blanca. El personaje trágico de Semíramis, necesariamente ambiguo -según la preceptiva aristotélica, afirmada y negada a un tiempo-, tiene así una doble faz política: es el triunfo militar, la fuerza de las armas victoriosas, la grandeza del Estado, pero es también la tiranía, la corrupción de la corte, donde las armas del valor y el esfuerzo ceden su papel a la simulación, la mentira y la crueldad ${ }^{21}$.

No hay, desde luego, una correlación mecánica entre Semíramis y Felipe II, ni mucho menos - salvo que hagamos una pirueta arriesgada-podemos ver la transposición de actores políticos del momento ${ }^{22}$. Sin embargo, como en el caso de esta tragedia, el Estado moderno, centralizado, expansivo y, también, intolerante e inquisitorial de Felipe II, ofrece la misma doblez faz: la victoria de Lepanto, la grandeza -y las dificultades-de un imperio, el orgullo de ser españoles en una Europa dominada por España y, por otra parte, la fijación de una corte en torno al rey - pálido anticipo del fulgor cortesano de los Austria menores-, el auge de la burocracia estatal y de la intolerancia organizada. En esas circunstancias, icómo sonará un parlamento como el de Diarco?:

¿Quién con rebelde corafón i infame sigue, aunque se interesse el bien del mundo, estos tiranos, bárbaros, crueles, que el cielo, para fuerte afote nuestro, por nuestras graves culpas, les da el mando, el poder i el govierno de la tierra? ${ }^{23}$

En el plano del haber político de Semíramis, ¿cómo no asociar el recuerdo de "la naval batalla» - a la que se dedica nada menos que treinta y ocho

21 Cfr. el artículo citado de A. Hermenegildo, "Adulación, ambición e intriga".

22 No resulta convincente ni documentada la opinión de Hermenegildo, expresada en el anterior artículo, de que esta tragedia refleja las intrigas de Antonio Pérez y la princesa de Éboli. Mucho más fácil seria ver el eco de la reclusión y muerte del príncipe don Carlos, pero aún esto es difícilmente sostenible con argumentos sólidos.

23 Poetas dramáticos valencianos, I, p. 52. El subrayado es nuestro. 
versos- con la de Lepanto, vivida por el propio Virués? ${ }^{24}$. ¿Cómo no recordar El Escorial ante la referencia a «las grandes obras i edificios / que a levantado" ? $^{25}$. Vanidad de vanidades, dirá Virués.

Para el soldado Virués, acostumbrado a poner «la vida en manos de la muerte $)^{26}$, el mundo cortesano es, lógicamente, la antítesis de las virtudes de la milicia. Es más, como ya ha señalado Hermenegildo, el mundo de la milicia se corrompe al contacto con la corte ${ }^{27}$. Un paso más y, si Semíramis no es transposición de persona concreta, si más bien es expresión alegórica de las peligrosas tendencias de un nuevo sistema, ino cabria verla como personificación del corazón de ese sistema, de la corte? En un larguísimo parlamento de Zelabo, en el tercer acto, la ambigüedad sintáctica apoya esa idea:

Sirvo en la guerra i en la corte, donde la fiel lealtad corrida el rostro esconde. La fiel lealtad que de la infiel tirana simulación el rostro esconde y huye, la cual de luz sofisticada i vana vestida, sus bellezas se atribuye, i tentadora ipócrita inumana paz i quietud, vida i onor destruye, i ambiciosa, insolente i temeraria es de virtud, sacrilega falsaria. ${ }^{28}$

Corte hermafrodita, tentadora y bella como la mujer, devoradora de soldados, insaciable... Ahí es donde reside, por desgracia, el poder. Al final, en la intervención de Tragedia, todos los elementos anteriores se contraponen sobre los dos platillos de la balanza:

24 Ibidem, pp. 54-55.

25 Ibidem, p. 55:

26 Ibidem, p. 34

Dilo tú, Babilonia ilustre i noble,

digalo tu sobervio i fuerte muro de ladrillo cozido, fabricado con hierro i con betún del Is asido, alto dozientos pies $i$ ancho cincuenta i que rueda diez leguas puesto en quadro...

27 "Los dos personajes. Zelabo y Zopiro, no son, en realidad, más que el desdoblamiento escénico de un solo carácter: el del cortesano, antiguo militar, corrompido..." ("Adulación, ambición e intriga), p. 55).

28 Poctas dramaticos valencianos. I, p. 50 


\begin{abstract}
De valor, de bondad, de cortesia, de engaño, de maldad i de malicia, de discreción, de amor, de valentía, de passión, de rencor i de cudicia, de vicio, de crueldad, de tirania, de govierno, de paz i de milicia, ilustre exemplo doi al alma ilustre con que su lustre como deve ilustre. ${ }^{24}$
\end{abstract}

Al cabo, la conclusión de Cristóbal de Virués no es optimista. Ninias, el sucesor, "en cuerpo i alma todo es cual su madre ${ }^{30}$. El exceso, el caos, continúa su reinado. La libertad, "que es el mayor tesoro" "31, no puede encontrarse en este mundo, «en guerra siempre armado, / do verdadera paz jamás se alcanza". ${ }^{32}$

29 Ibidem, p. 57.

30 Ibidem.

31 Ibidem, p. 50.

32 Poemas épicos, I, p. 560. 